\title{
Numerical and Experimental Research on the Influence of Clearance Between Impeller and Cover on the Pump Performance
}

\author{
Guangjie PENG*,***, Shiming HONG*, Hao CHANG*, Fengyi FAN*, Yiyang ZHANG**, \\ Peng SHI**** \\ *Research Center of Fluid Machinery Engineering and Technology, Jiangsu University, Zhenjiang, 212013, China, \\ E-mails: pgj@ujs.edu.cn, changhao@ujs.edu.cn \\ **China Water Resources Beifang Investigation Design and Research Co. Ltd., Tianjin, 300222, China \\ ***Zhenjiang Research Institute of Fluid Engineering Equipment Technology, Jiangsu University, Zhenjiang, 212013 , \\ China \\ ****Electro-Mechanical General Factory, Jiangsu University, Zhenjiang, 212013, China \\ crossref http://dx.doi.org/10.5755/j02.mech.28904
}

\section{Introduction}

Centrifugal pumps play an important role in the national economy which are widely used in many fields such as agriculture, industry and urban water supply and drainage. However, the energy consumption of centrifugal pump accounts for about $1 / 12$ of the total power generation in China. Therefore, improving the efficiency of centrifugal pumps is an important goal of the industry.

According to engineering and experiments, it found that all clearances between parts of centrifugal pump have a significant impact on the hydraulic performance. Unreasonable clearance values will cause large leakage losses and vortex flow, which will reduce the efficiency of the pump. What is more, ring clearance, blade tip clearance and clearance between the impeller and pump cover are three main types of clearance of centrifugal pump. At present, many scholars have carried out the researches on the impeller wear ring clearance and blade tip clearance of centrifugal pump. Daqiqshiraz M et al. [1] employed the CFX to investigate the influence of wear ring clearance on the overall efficiency of low specific speed centrifugal pump, it found that volumetric efficiency decreases effectively by improving the ring clearance more than three times. Shi Weidong et al. [2] studied effect of wear-ring clearance on performance of a submersible well pump combine the experiment and calculation, it concluded that when the clearance is larger than $0.5 \mathrm{~mm}$, the hydraulic performance of the pump is significantly decline. Liu Houlin et al. [3] compared the performance, pressure pulsations, hydraulically generated vibration and noise level with different wear ring clearance, and the optimal parameter of wear-ring clearance was obtained. Hao Yue et al. [4] proposed the mixed flow pump with symmetrical and unsymmetrical tip clearance, and the cavitation characteristic and radial force were analyzed by experimental and numerical. Feng Jianjun et al. [5] employed numerical method to study the influence of tip clearance on pressure fluctuations of axial flow water pump, by comparing three different tip clearance, it found that the pressure fluctuations in the impeller is obviously larger than the diffuser. Liu Yabin et al. [6-7] studied the relationship between the leakage vortex and tip clearance by calculation, the investigation result showed that the strength of leakage vortex is gradually improved when the size of tip clearance consciously increases. Kim Changhyun et al. [8] proposed four different sizes of inducer tip clearances, and hydraulic performance under cavitation condition and non-cavitation condition was analyzed by simulation. Shi Guangtai et al.
[9] analyzed the internal flow and velocity distribution characteristics of the multiphase pump under different tip clearances, by employing the high-speed photography and numerical simulation, it found that tip leakage vortex has significant effect on the tip separated vortex and the hydraulic loss of pump. Li Wei et al. [10-11] proposed a mixed-flow pump model with non-uniform tip clearance, through the technology of particle image velocimetry to analyze the effect of flow rate and eccentricity on the flow characteristics. Parikh Trupe et al. [12] employed the Volume of Fluid (VOF) method and k-omega SST model to conduct the transient simulations of centrifugal pumps, and the relationship between the tip clearance gap and transport of air-water twophase flow was obtained.

Nevertheless, plenty of investigation of impeller wear ring clearance and blade tip clearance of centrifugal pump was conducted, only few studies [13-14] focus on the clearance between the impeller and pump cover. Therefore, in this paper, the influence of clearance between impeller and pump cover on the hydraulic characteristic by numerical simulation was analyzed, and the hydraulic experiment with different clearance was carried out. The research results have significant guiding effect for the design of clearance between impeller and cover in the future.

\section{Research models and numerical calculation methods}

\subsection{Control equations and solutions}

In this paper, the continuity equation of incompressible fluid and the Navier-Stokes equation were employed. The continuity equation of incompressible fluid and the Navier-Stokes equation are applicable to describe the three-dimensional turbulence in a centrifugal pump.

The continuity equation:

$$
\frac{\partial\left(\rho u_{i}\right)}{x_{i}}=0
$$

N-S equation for incompressible fluid:

$$
\frac{\partial\left(\rho u_{i}\right)}{\partial t}+\frac{\partial\left(\rho u_{i} \rho u_{j}\right)}{\partial x_{j}}=-\frac{\partial p}{\partial x_{j}}+\rho F_{i}+2 \frac{\partial\left(\mu S_{i j}\right)}{\partial x_{j}}
$$

In the formula: $\rho$ is fluid density; $t$ is time; $F_{i}$ is the volume force component of a fluid per unit mass; $P$ is pressure; $u_{i}, u_{j}(i, j=1,2,3 ;)$ is the velocity component of the fluid; 
$x_{i}, x_{j}(i, j=1,2,3 ;)$ is coordinate component; $\mu$ is molecular viscosity coefficient; $s_{i j}$ : is the fluid deformation rate tensor

$$
S_{i j}=\frac{1}{2}\left(\frac{\partial u_{i}}{\partial x_{j}}+\frac{\partial u_{j}}{\partial x_{i}}\right) \text {. }
$$

In this paper, Reynolds average method [15 - 16] is used to solve the above governing equation, and the twoequation model in vortex-viscous model is used to close the equations. According to the flow characteristics inside the centrifugal pump, the $S S T K-\omega$ turbulence model was selected to predict the separation flow, reflux and large curvature flow. Coupling of pressure and velocity is realized based on SIMPLEC algorithm (just improve the coefficient during the velocity-correction equation), that can speed up convergence and improve calculation efficiency. The governing equation is discretized by finite volume method. High Resolution discrete scheme was used for convection term and the diffusion term adopts the central difference scheme.

\subsection{Physical model and boundary conditions}

In this study, the flow field of a centrifugal slurry pump at the $\mathrm{Q}_{\mathrm{BEP}}$ (Best Efficiency Point, BEP) was analyzed. The pump speed was $1000 \mathrm{r} / \mathrm{min}$, the flow rate was $288 \mathrm{~m}^{3} / \mathrm{h}$, the head was $11.5 \mathrm{~m}$, the inlet diameter was $175 \mathrm{~mm}$, the outlet diameter was $150 \mathrm{~mm}$, the impeller had 3 blades, and the impeller outer diameter was $310.4 \mathrm{~mm}$.

The physical model was established by 3D modeling software Unigraphics NX, and the results were shown in Fig. 1. According to the characteristics of the calculation domain, the pump is divided into six parts, namely inlet, impeller, volute, auxiliary vane area, front pump cavity and rear pump cavity. In addition, the front pump cavity is divided into two calculation domains, one is the auxiliary blade domain, which was set as the rotation domain with the same speed as the impeller. The other part is the front pump cavity, which was set as the static domain. What is more, the models with different axial clearances were obtained by changing the axial position of the impeller. When the front cover is completely fitted to the wall of the pump chamber, it is defined as a model with a clearance of $0 \mathrm{~mm}$.

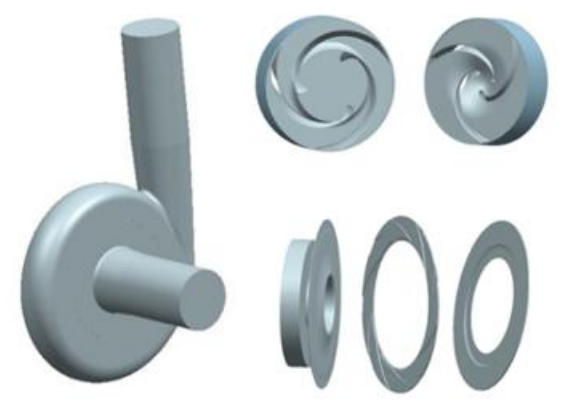

Fig. 1 3D model of centrifugal pump

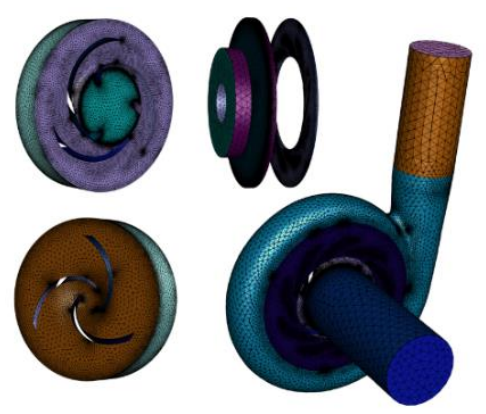

Fig. 2 Mesh generation

Considering the complexity of the simulation model, hybrid unstructured grid with tetrahedral elements was applied to discretize the domains. In order to capture the details of the internal flow field, local encryption was employed on the clearance and tongue. And the results of mesh generation are shown in Fig. 2. The total number of mesh nodes of centrifugal pump is 561,000 , and the total number of elements is about 2,356,000. The number of mesh nodes and elements of each part is shown in Table 1.

Meanwhile, the boundary conditions are set as follows: the inlet of the pump is set as the mass flow, assuming that the flow direction is perpendicular to the inlet, and the different mass flow values are given under different operating conditions. The pump outlet boundary is set as average static pressure. In addition, the impeller field and the auxiliary blade field are set as the rotating field, and the rotating speed is $1000 \mathrm{r} / \mathrm{min}$.

Table 1

Number of grids in each computational domain

\begin{tabular}{|c|c|c|c|c|cc|c|}
\hline & Inlet & Impeller & Volute & Auxiliary vane & Front pump cavity & Back pump cavity \\
\hline Nodes (ten thousand) & 8.6 & 21.8 & 18.3 & 1.3 & 2.1 & 4.0 \\
\hline Elements (ten thousand) & 8.2 & 110.2 & 95.2 & 4.4 & 1.3 & 16.3 \\
\hline
\end{tabular}

The other calculation fields are set as the stationary field. Frozen rotor was set as the interface between the rotating field and stationary field. The wall of front and back cover plates was set as rotating walls, and the rotating speed was also $1000 \mathrm{r} / \mathrm{min}$. All domain walls are set as no slip walls. Standard wall functions are used in the near wall region. Considering the convergence speed and calculation accuracy, the time step is set as $0.01 \mathrm{~s}$.

When the average residuals of each item are less than 0.0001 , the calculation is considered to be convergent.

\subsection{Grid independence analysis}

Several meshes were used to evaluate the influence of the number of elements based on the pump head and pump efficiency for the same flow conditions. Table 2 compares the predictions for four meshes. Even with a large number of elements, the predicted heads were all within $0.3 \%$, and the pump efficiencies were within $2 \%$. Thus, with 2.35 million elements, the predicted head and efficiency were within $1 \%$ of the results with the largest mesh, so the smallest number of elements was considered appropriate.

\section{Experiment verification}

In order to verify the accuracy of the numerical simulation method, the hydraulic performance experiment under $0 \mathrm{~mm}$ clearance (For better understanding, the clearance less than $0.01 \mathrm{~mm}$ is defined as $0 \mathrm{~mm}$ clearance) was carried out. The hydraulic performance characteristic curve 
is shown in Figs. 3 and 4. The calculation results are consistent with the experiment, especially in the optimal and over-load flow conditions, the efficiency deviation is less than $1 \%$; while the efficiency value calculated in the partload flow condition is higher, the maximum error is $2.4 \%$. Meanwhile, the calculated error of head is within $0.4 \mathrm{~m}$, and the relative error is within $4 \%$, which ensure the accuracy of numerical simulation method for further internal flow field analysis.

Table 2

Performance comparison with various numbers of elements for the $Q_{B E P}$ flow conditions

\begin{tabular}{|c|c|c|}
\hline Number of elements & Predicted head, $\mathrm{m}$ & Pump efficiency, $\%$ \\
\hline 2356139 & 11.52 & 84.2 \\
\hline 4278364 & 11.45 & 83.8 \\
\hline 7308476 & 11.22 & 83.3 \\
\hline 9205483 & 10.98 & 82.7 \\
\hline
\end{tabular}

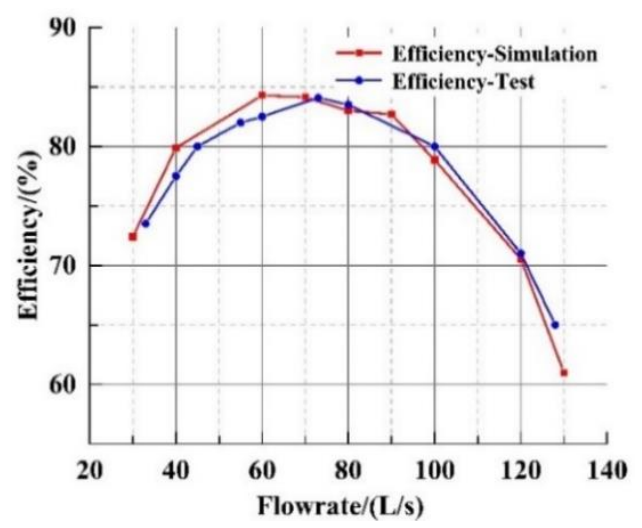

Fig. 3 The efficiency-flowrate curve under clearance of $0 \mathrm{~mm}$

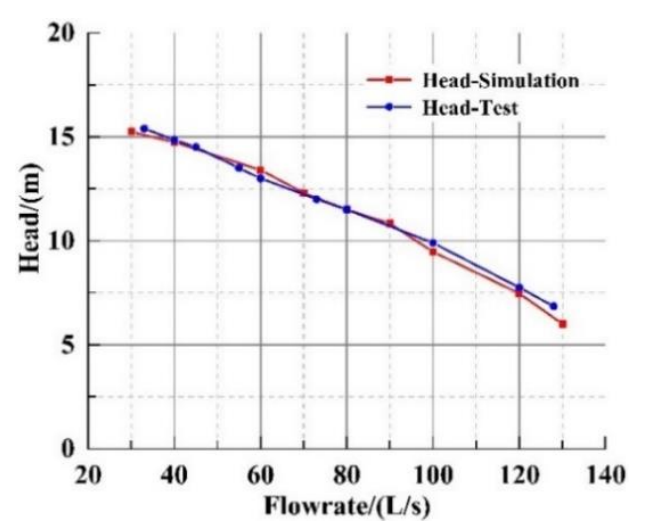

Fig. 4 The head-flowrate curve under clearance of $0 \mathrm{~mm}$

In this paper, three different flow conditions were selected for flow analysis, namely, optimal flow condition $(Q=80 \mathrm{~L} / \mathrm{s})$, part-load flow condition $(Q=40 \mathrm{~L} / \mathrm{s})$, and over-load flow condition $(Q=120 \mathrm{~L} / \mathrm{s})$. Fig. 5 presents the static pressure distribution in the middle section of the centrifugal pump. As the flowrate increases, the pressure in the pump gradually improves. Furthermore, an obvious lowpressure area on the inlet of suction surface can be found under part-load flow condition. And under the part-load flow condition and optimal flow conditions, the pressure increases from impeller inlet to the volute outlet. While under over-load flow conditions, the pressure of volute diffuser section decreases significantly compared with that in the volute. As the flowrate increases, pressure increment gradually decreases from impeller inlet to the outlet of volute, which result in the reduction of head. What is more, the pressure distribution in the impeller and volute is more uniformly in the circumferential direction under part-load condition, the obvious pressure fluctuation can be found near the tongue. Furthermore, under the optimal flow condition, the pressure increase uniformly from the impeller inlet to the outlet, but the local pressure distribution in the volute is relatively disorder. When the flow rate increase to $120 \mathrm{~L} / \mathrm{s}$, an obvious high-pressure area appears can be observed at the impeller outlet, and the pressure near the tongue variation drastically.
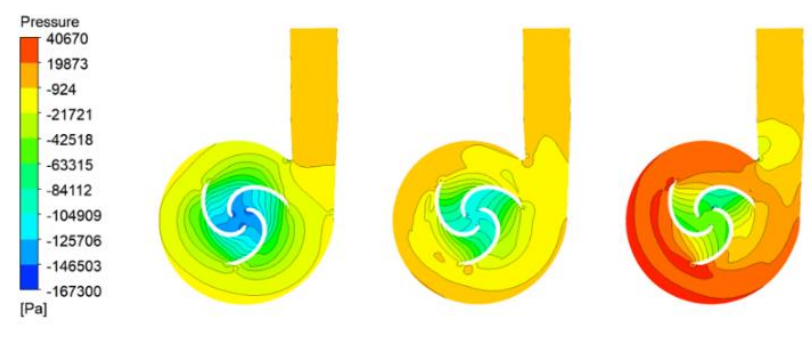
a) $Q=40 \mathrm{~L} / \mathrm{s}$
b) $Q=80 \mathrm{~L} / \mathrm{s}$
c) $Q=120 \mathrm{~L} / \mathrm{s}$

Fig. 5 Static pressure distribution in the middle section of a centrifugal pump

Fig. 6 is the absolute velocity distribution of the middle section of centrifugal pump. Under different flowrates, the velocity distribution of internal flow field exists large difference. As the flowrate increases, the flow velocity in the runner decreases significantly. Under the partload flow conditions, the velocity is gradually decrease from the impeller outlet to volute outlet, and the kinetic energy is converted into potential energy in the diffusion section of the volute. Meanwhile, the velocity variation in the volute is small under optimal flow condition, but a local low-velocity zone was found at the tongue of volute, which result from the generation of the flow separation. What is more, due to the effect of the backflow and vortex, there is a large lowvelocity area in the volute under over-load flow conditions. At the same time, the flow velocity of the diffusion section increases significantly, and the potential energy is transformed into kinetic energy, which resulting in the hydraulic loss and head reduction.
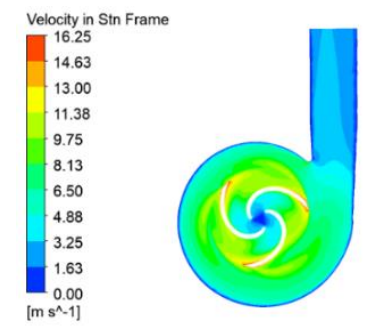

a) $Q=40 \mathrm{~L} / \mathrm{s}$

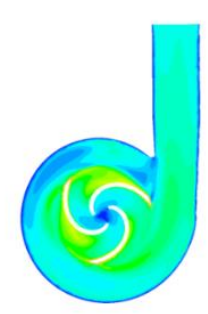

b) $Q=80 \mathrm{~L} / \mathrm{s}$

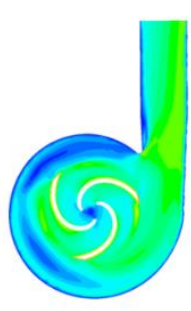

c) $Q=120 \mathrm{~L} / \mathrm{s}$
Fig. 6 Absolute velocity distribution in the middle section of a centrifugal pump

Figs. 7 and 8 are the streamline distribution of the middle section of centrifugal pump and velocity vector distribution at the tongue respectively. The obvious leakages and vortices were found in the impeller flow passage under part-load flow conditions, which block the flow passage and restrain the work of the impeller. At the same time, a circulation flow was generated result from the impaction of water 
on the tongue. With the flow rate increase to the optimal flow condition, the flow separation in the impeller and circulation flow at the tongue have been effectively improved, and the impaction of tongue is gradually decrease. Meanwhile, under the over-load flow conditions, the flow in the impeller channel is very smooth, but a severe impaction was generation at the outlet of impeller, which result in a large area of backflow in the volute. Furthermore, an obvious rotor-stator interaction can be found near the tongue, which cause the serious hydraulic loss of internal flow field.

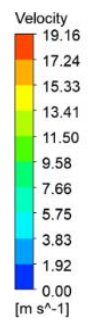

a) $Q=40 \mathrm{~L} / \mathrm{s}$

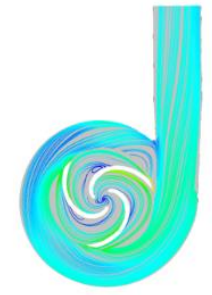

b) $Q=80 \mathrm{~L} / \mathrm{s}$

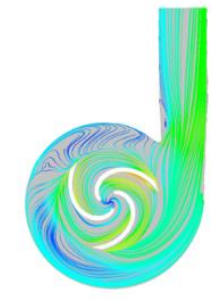

c) $Q=120 \mathrm{~L} / \mathrm{s}$
Fig. 7 Streamline distribution in the middle section of a centrifugal pump

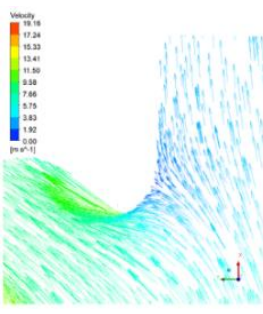

a) $Q=40 \mathrm{~L} / \mathrm{s}$

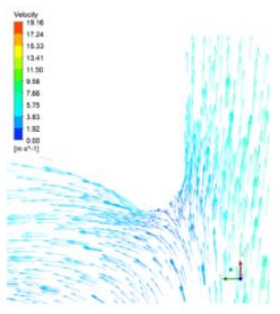

b) $Q=80 \mathrm{~L} / \mathrm{s}$

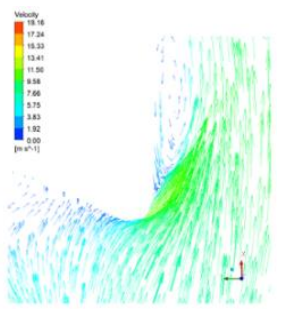

c) $Q=120 \mathrm{~L} / \mathrm{s}$
Fig. 8 Velocity vector distribution near the separating tongue of centrifugal pump

\section{Analysis of flow characteristics under different clear- ance}

Calculation domains of five centrifugal pump models with different axial clearances $(0,0.1,0.22,0.42$, $0.62 \mathrm{~mm}$ ) were built, and the numerical simulation under the optimal flow condition were carried out. Meanwhile, the clearance leakage flow was monitored in the calculation, as shown in the Table 3. Considering the flow into the rear pump cavity under different clearances is less than $0.0001 \mathrm{~L} / \mathrm{s}$, so the leakage loss of the rear pump cavity can be ignored. What is more, it found that fluid leaks from the high-pressure volute into the low-pressure pump cavity, and one part of leakage fluid under the effect of auxiliary vane flow into the volute, other part flows back to the impeller inlet, which induce to the generation of leakage losses. However, when the clearance is $0 \mathrm{~mm}$, fluid cannot flow from the front pump cavity into the inlet. Therefore, under the effect of auxiliary vanes, the fluid returns to the volute without leakage loss. At the same time, as the axial clearance increases, the flowrate of leakage into the front pump cavity and flow back to the inlet gradually increases, while the flowrate return to the volute by auxiliary vanes gradually decreases, and the flowrate flowing back to the impeller inlet increases. Therefore, the leakage loss increases and the efficiency of the centrifugal pump decreases.

Fig. 9 shows the streamline distribution in middle section of centrifugal pump and velocity vector distribution near the tongue under different clearances. With the increase of the clearance, the overall flow state is similar, the flow separation on the pressure surface of blade inlet is slightly increased, which indicates that the variation of clearance has little effect on the mainstream of pump. Furthermore, when the clearance is $0 \mathrm{~mm}$ and $0.1 \mathrm{~mm}$, the flow impaction on the tongue is obviously less than the clearance is $0.22 \mathrm{~mm}$ and $0.42 \mathrm{~mm}$, and the fluid flows smoothly along the flow channel. However, when the clearance increases to $0.62 \mathrm{~mm}$, the strong impaction was generated at the tongue of volute, which result in great hydraulic loss of pump.

Fig. 10 shows the absolute velocity distribution of centrifugal pump in the vertical axis section. Under different clearance conditions, the absolute velocity distribution present the similar variation trend. The absolute velocity gradually increases from impeller inlet to outlet. After fluid entering into the volute, the absolute velocity gradually decreases, and the kinetic energy is transformed into pressure energy. Due to the velocity distribution of the pump is asymmetry, which lead to the flow in the volute is more turbulent, and the vortex movement is obvious. As shown in the Fig. 10, as the clearance increases, the absolute speed in the front pump cavity decreases. The auxiliary vane can only make adjacent fluid flow back to the volute, and other fluid without the effect of auxiliary vane flow through the clearance into the impeller inlet. Therefore, the larger the clearance, the greater the leakage is generated in the internal flow. In addition, the fluid flowing out of the clearance interferes with the flow of the impeller inlet. With the increase of clearance, the interference effect is gradually enhanced, and the low-speed area at suction surface of the blade inlet is increased, namely, the more severe flow separation is generated.

Table 3

Leakage flowrate of different clearances

\begin{tabular}{|c|c|c|c|c|c|}
\hline Axial clearance, $\mathrm{mm}$ & 0 & 0.1 & 0.22 & 0.42 & 0.62 \\
\hline From the volute into the front pump cavity, $L / s$ & 1.23 & 1.4 & 1.71 & 2.27 & 2.61 \\
\hline From the front pump cavity into the auxiliary vane domain, $L / s$ & -1.23 & -1.18 & -1.09 & -0.87 & -0.74 \\
\hline From the front pump cavity back to the impeller inlet, $L / s$ & 0 & -0.22 & -0.62 & -1.40 & -1.87 \\
\hline
\end{tabular}

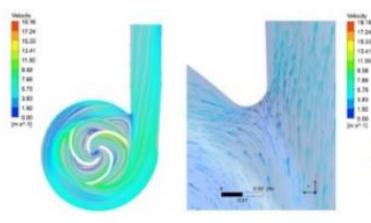

a) $0 \mathrm{~mm}$

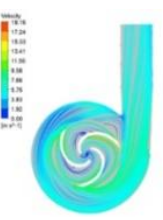

b) $0.1 \mathrm{~mm}$

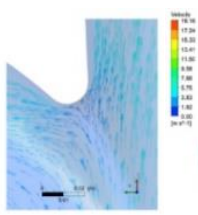

(5)

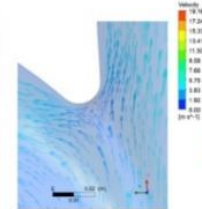

c) $0.22 \mathrm{~mm}$

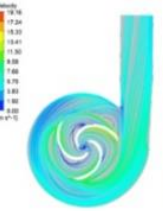

d) $0.42 \mathrm{~mm}$

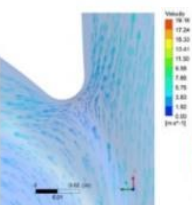

(5)
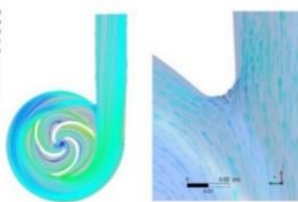

e) $0.62 \mathrm{~mm}$

Fig. 9 Streamline distribution in the middle section of centrifugal pump 
a) $0 \mathrm{~mm}$

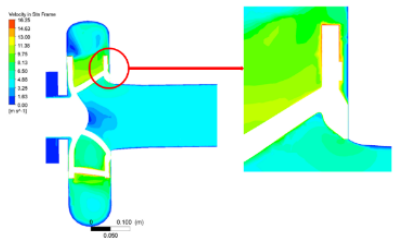

c) $0.22 \mathrm{~mm}$

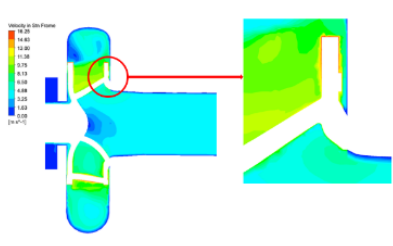

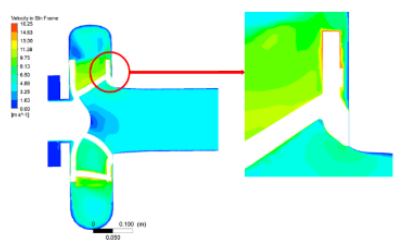

b) $0.1 \mathrm{~mm}$

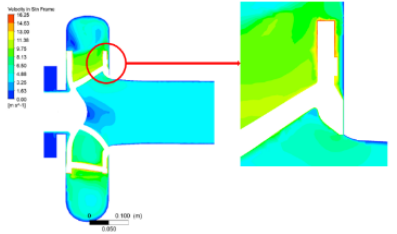

d) $0.42 \mathrm{~mm}$

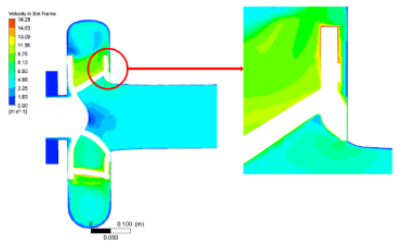

e) $0.62 \mathrm{~mm}$

Fig. 10 The absolute velocity distribution of the vertical axis section of the centrifugal pump

\section{Hydraulic experiment with different clearance}

In this paper, in order to ensure the accuracy of the previous investigation, the experiment rig is built, and the hydraulic experiment with four clearances under different flow conditions were carried out. The experiment is to change the clearance between the front cover and the pump cover by adjusting the bearing assembly of the model pump. When the front cover is completely fitted to the wall of the pump chamber, it is defined as a model with a clearance of $0 \mathrm{~mm}$. The experiment rig is shown in the Fig. 11.

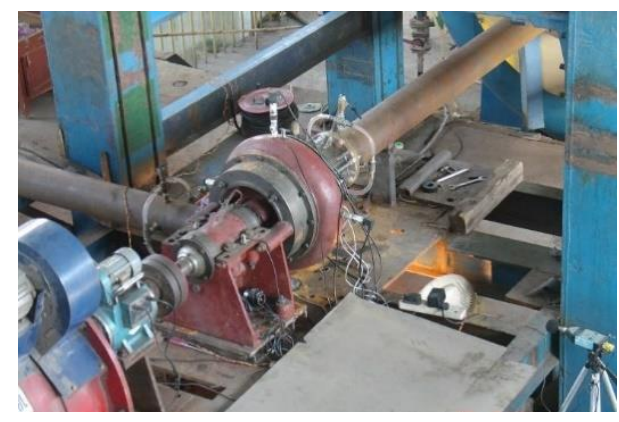

Fig. 11 The experiment rig

All transducer has been calibrated before the experiment, the deviation of electromagnetic flowmeter is less than $\pm 0.2 \%$, the deviation of head transducer is less than $\pm 0.1 \%$ and the torque speed sensor is less than $\pm 0.1 \%$. As shown in the Figs. 12 and 13, according to the result of the hydraulic experiment, it found that as the increase of the clearance, the head and efficiency gradually decrease. Meanwhile, the decrement is increases constantly. This phenomenon is attribute to the fluid flow back to the impeller through the clearance, with the increase of clearance, the backflow is obviously improved, which result in improvement of volume loss. Therefore, the head and efficiency present significant decline trend.

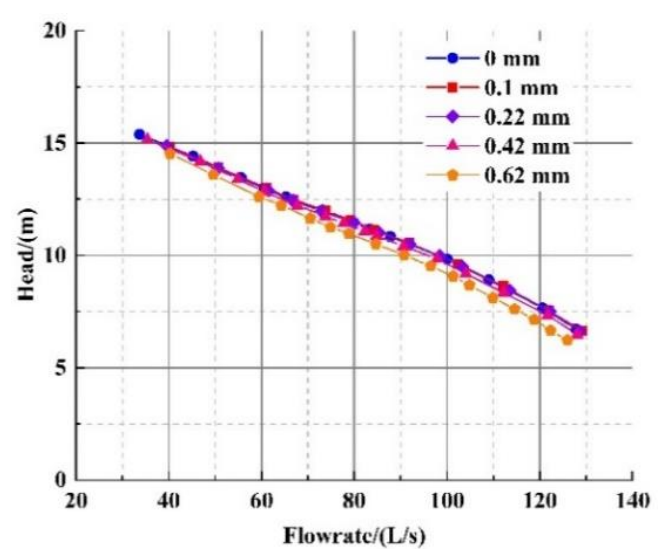

Fig. 12 The experiment result of head

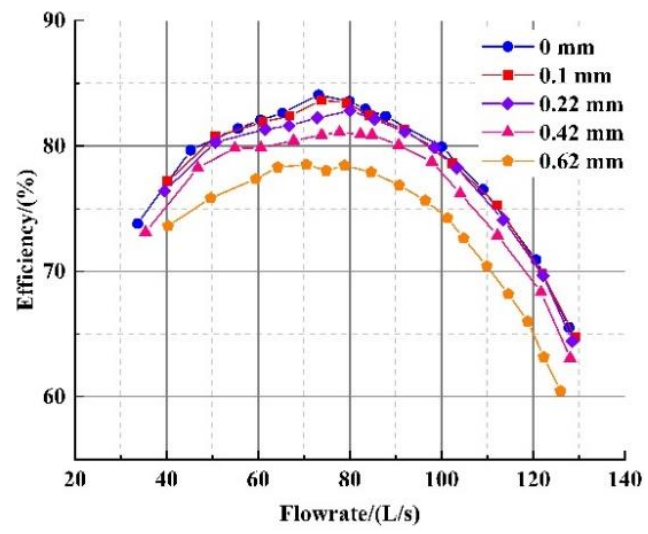

Fig. 13 The experiment result of efficiency

\section{Conclusion}

In this paper, the calculation model with different clearance were established, and in order to verifies the accuracy of the numerical simulation, the hydraulic experiment under different flow conditions was carried out. When establishing the physical model, the front and rear pump cavities were considered. According to the investigation of numerical simulation and experiment, the conclusions can be obtained as follow:

1) The flow field characteristics of centrifugal pumps with $0 \mathrm{~mm}$ clearance are analyzed. The results show that as the flowrate increases, the pressure inside the impeller increases. Under part load flow conditions, the pressure distribution of impeller and volute is uniform in the circumferential direction, and the great radial pressure gradient is generated. With the flowrate increase to the over-load flow conditions, an obvious high-pressure area was found at the outlet of impeller, and the dramatic pressure fluctuation is generated at the tongue.

2) The hydraulic loss of the part load flow condition is mainly caused by the leakage in impeller and circulating flow in volute, while the hydraulic loss of the overload flow condition is mainly result from the large-area backflow in the volute.

3) By comparing the calculation results of different clearance models under the optimal flow conditions, it is found that as increases of clearance, the fluid flow from the front pump cavity into the impeller inlet is gradually increases. Meanwhile, due to the limited range effect of the auxiliary blades, the fluid flow back to the volute is decline. In addition, the fluid flowing out of the clearance interferes with the flow of the impeller inlet. With the increase of clearance, the interference effect is gradually enhanced, and 
the low-speed area at suction surface of the blade inlet is increased, namely, the more severe flow separation is generated.

\section{References}

1. Daqiqshiraz, M.; Torabi, R.; Rias, A. et al. 2017. The effect of wear ring clearance on flow field in the impeller sidewall gap and efficiency of a low specific speed centrifugal pump, Proceedings of the Institution of Mechanical Engineers, Part C: Journal of Mechanical Engineering Science.

2. Shi, W.; Gao, X.; Zhang, Q. et al. 2017. Numerical investigations on effect of wear-ring clearance on performance of a submersible well pump, Advances in Mechanical Engineering 9(7): 1687814017704155.

3. Liu, H.; Ding, J.; Dai, H. et al. 2015. Effects of wear ring clearance on hydraulically generated vibration and noise of a centrifugal pump volute, Journal of Vibroengineering 17(3): 1142-1156.

4. Hao, Y.; Tan, L. 2018. Symmetrical and unsymmetrical tip clearances on cavitation performance and radial force of a mixed flow pump as turbine at pump mode, Renewable Energy 127: 368-376.

5. Feng, J.; Luo, X.; Guo, P. et al. 2016. Influence of tip clearance on pressure fluctuations in an axial flow pump, Journal of Mechanical Science and Technology 30(4): 1603-1610.

6. Liu, Y.; Tan, L.; Hao, Y. et al. 2017. Energy performance and flow patterns of a mixed-flow pump with different tip clearance sizes, Energies 10(2): 191.

7. Liu, Y.; Han, Y.; Tan, L. et al. 2020. Blade rotation angle on energy performance and tip leakage vortex in a mixed flow pump as turbine at pump mode, Energy 206: 118084.

8. Changhyun Kim, Semi Kim et al. 2017. Effects of inducer tip clearance on the performance and flow characteristics of a pump in a turbopump, Proceedings of the Institution of Mechanical Engineers, Part A. Journal of power and energy 231(A5): 398-414.

9. Shi, G.; Liu, Z.; Xiao, Y. et al. 2020. Velocity characteristics in a multiphase pump under different tip clearances, Proceedings of the Institution of Mechanical Engineers, Part A: Journal of Power and Energy: 0957650920946533.

10. Li, W.; Ji, L.; Shi, W. et al. 2020. Particle image velocimetry measurement of flow fields in a mixed-flow pump with non-uniform tip clearance, Journal of Visualization: 1-17.

11. Ji, L.; Li, W.; Shi, W. et al. 2020. Transient characteristics of internal flow fields of mixed-flow pump with different tip clearances under stall condition, Proceedings of the Institution of Mechanical Engineers, Part A: Journal of Power and Energy: 0957650920962250.

12. Parikh, T.; Mansour, M.; Thevenin, D. 2020. Investigations on the effect of tip clearance gap and inducer on the transport of air-water two-phase flow by centrifugal pumps, Chemical Engineering Science 218: 115554.

13. Li, C.; Xue, Z.; Li, H. 2016. Effects of axial clearances between impeller front shroud and pump body on axial force, Journal of Drainage and Irrigation Machinery Engineering 34(4): P295-300: 1674-8530.
14. Zhang, Y.; Jia, R.; Yan, Y.; Zhang, Z. 2017. Research on influences on operation performance exerted by change in clearance between centrifugal pump impeller and pump cover, Mechanical \& Electrical Technique of Hydropower Station 40(5): P11-14,20: 1672-5387.

15. Peng, G.; Huang, X.; Zhou, L. et al. 2020. Solid-liquid two-phase flow and wear analysis in a large-scale centrifugal slurry pump, Engineering Failure Analysis 114: 104602.

16. Pang, Q.; Jiang, X.; Zhu ,J. et al. 2019. Influences of radial clearance between impeller and diffuser on flow field in side chambers of multistage centrifugal pump, J. Drain. Irrig. Mach. Eng, 37: 580-586.

\section{G. Peng, Sh. Hong, H. Chang, F. Fan, Y. Zhang, P. Shi}

NUMERICAL AND EXPERIMENTAL RESEARCH ON THE INFLUENCE OF CLEARANCE BETWEEN IMPELLER AND COVER ON THE PUMP PERFORMANCE

S u m m a r y

Centrifugal pump is widely used and plays an important role in national economy. However, according to plenty of engineering practice and model tests, it indicated that the clearance between the impeller and pump cover is an important parameter for leakage loss and hydraulic efficiency. In this paper, a single stage centrifugal pump was selected to study the influence of clearance between impeller and pump cover on the hydraulic performance through combination of experiment and numerical simulation. Commercial software ANSYS CFX was employed to simulate the internal flow field with a clearance of $0 \mathrm{~mm}$, and the experimental verification was carried out. The results presented that only a small difference was generated between experiment and numerical simulation, the maximum error is less than $4 \%$, which can ensure the accuracy of the numerical calculation. At the same time, by comparing the simulation results with clearance of $0.1,0.22,0.42$ and $0.62 \mathrm{~mm}$, it found that with the increase of clearance, the impact loss at the tongue was significantly improved. In addition, with the increase of clearance, the effect of water flowing out from clearance interferes with the water at impeller inlet gradually improve. Finally, the hydraulic experiment with different clearance were carried out to verify the numerical result. Therefore, this research results have significant guiding effect for the design of clearance between impeller and cover in the future.

Keywords: centrifugal pump, clearance, experiment, numerical simulation.

Received April 13, 2021

Accepted February 04, 2022 